\title{
M-Mode Ultrasound Mode
}

National Cancer Institute

\section{Source}

National Cancer Institute. M-Mode Ultrasound Mode. NCI Thesaurus. Code C130063.

A method of ultrasound imaging that uses a single ultrasound beam to provide high temporal resolution of tissue motion. 